\title{
Expression of Concern to: Redox modification of cysteine residues regulates the cytokine activity of high mobility group box-1 (HMGB1)
}

Huan Yang ${ }^{1}$, Peter Lundbäck ${ }^{2}$, Lars Ottosson ${ }^{2}$, Helena Erlandsson-Harris ${ }^{2}$, Emilie Venereau ${ }^{3}$, Marco E. Bianchi $^{3}$, Yousef Al-Abed ${ }^{4}$, Ulf Andersson ${ }^{2}$, Kevin J. Tracey ${ }^{1}$ and Daniel J. Antoine ${ }^{5^{*}}$

Expression of Concern to: Mol Med (2012) 18:250-259

https://doi.org/10.2119/molmed.2011.00389

The Editors-in-Chief would like to alert readers that this article (Yang et al. 2012) is part of an investigation being conducted by the journal following the conclusions of an institutional enquiry at the University of Liverpool with respect to the quantitative mass spectrometrygenerated results regarding acetylated and redox-modified HMGB1. Appropriate editorial action will be taken once the investigation is concluded.

Huan Yang, Peter Lundbäck, Lars Ottosson, Helena Erlandsson-Harris, Emilie Venereau, Marco E. Bianchi, Yousef Al-Abed, Ulf Andersson, and Kevin J. Tracey agree to this editorial expression of concern.

Daniel J. Antoine has not responded to any correspondence from the editor/publisher about this editorial expression of concern.

\section{Author details}

${ }^{1}$ Laboratory of Biomedical Science, The Feinstein Institute for Medical Research, Manhasset, New York, USA. ${ }^{2}$ Departments of Women's and Children's Health, Medicine and Rheumatology Research Laboratory, Karolinska Institutet and Karolinska University Hospital, Stockholm, Sweden. ${ }^{3}$ San Raffaele University and Scientific Institute, Milan, Italy. ${ }^{4}$ Department of Medicinal Chemistry, The Feinstein Institute for Medical Research, Manhasset, New York, USA. ${ }^{5}$ MRC Centre for Drug Safety Science, Department of Molecular and Clinical Pharmacology, University of Liverpool, Liverpool, UK.

Published online: 04 February 2020

\section{Publisher's Note}

Springer Nature remains neutral with regard to jurisdictional claims in published maps and institutional affiliations.

\section{Reference \\ Yang $\mathrm{H}$, et al. Redox modification of cysteine residues regulates the cytokine activity of high mobility group box-1 (HMGB1). Mol Med. 2012;18:250-9.} https://doi.org/10.2119/molmed.2011.00389.

\footnotetext{
* Correspondence: d.antoine@liv.ac.uk

${ }^{5}$ MRC Centre for Drug Safety Science, Department of Molecular and Clinical

Pharmacology, University of Liverpool, Liverpool, UK

Full list of author information is available at the end of the article
}

(c) The Author(s). 2020 Open Access This article is distributed under the terms of the Creative Commons Attribution 4.0 International License (http://creativecommons.org/licenses/by/4.0/), which permits unrestricted use, distribution, and reproduction in any medium, provided you give appropriate credit to the original author(s) and the source, provide a link to the Creative Commons license, and indicate if changes were made. The Creative Commons Public Domain Dedication waiver (http://creativecommons.org/publicdomain/zero/1.0/) applies to the data made available in this article, unless otherwise stated. 